\title{
Neonatal Hyperbilirubinemia: A Retrospective Study
}

\author{
Hina Abbas', Sabih ul Hassan², Kulsoom Arif, Sambreen Zameer ${ }^{1}$, Naseem Ahmed', Aisha Abdul Haq ${ }^{1}$
}

\begin{abstract}
Background: Neonatal Hyperbilirubinemia is a common problem encountered in neonates and often requires admission and treatment. Almost $60 \%$ of the term babies and $80 \%$ of the preterm babies develop jaundice. East Asians have higher baseline neonatal bilirubin levels than whites and are predisposed to the development of severe neonatal hyperbilirubinemia.

Objectives: To determine the important prognostic factors in Neonatal Hyperbilirubinemia and to correlate variables with severity of presentation.

Material and Methods: A retrospective study was conducted in the Paediatrics Unit 3 of Civil Hospital Karachi from June to November 2017 on admitted patients below one month of age with clinically diagnosed jaundice. Total and indirect serum bilirubin levels, and data of gender, age, birth weight, blood group incompatibility, and breast feeding were obtained.

Results: Of 255 cases, $80 \%$ were resolved. Phototherapy was the most common method of treatment (in $91.8 \%$ of cases). Males slightly outnumbered females (1.39:1). 6.3\% of jaundiced neonates died; $3.5 \%$ developed kernicterus before death. Low birth weight was observed in $50.2 \%$ of cases while preterm gestation was seen in $39.2 \%$ of cases.

Conclusion: Important prognostic factors for Hyperbilirubinemia were presence of kernicterus, anemia, age group of the infant, severity of hyperbilirubinemia and the therapy provided.

Keywords: Neonatal hyperbilirubinemia; Preterm; Kernicterus; Low Birth Weight
\end{abstract}

This article may be cited as: Abbas H, Hassan S, Arif K, Zameer S, Ahmed N, Haq AA

Neonatal Hyperbilirubinemia: A Retrospective Study. J Saidu Med Coll Swat 2020;10(1):52- 55

\section{INTRODUCTION}

The great burden imposed by neonatal hyperbilirubinemia is exemplified by the fact that globally; about $60 \%$ of the term babies and $80 \%$ of the preterm babies develop jaundice ${ }^{1}$. Neonatal jaundice also happens to be the most common cause of neonatal hospital readmission. The trends of neonatal hyperbilirubinemia vary between developing and developed countries with research still underway to pinpoint the causes of such disparities $^{3,4,5}$. Neonatal hyperbilirubinemia has a plethora of causes, both pathological and physiological ${ }^{6}$. While the physiological causes include breast-feeding and high cell turnover in relation to clearance of bilirubin, the pathological causes are divided into three categories: increased bilirubin load, decreased bilirubin conjugation, and impaired bilirubin excretion ${ }^{7}$. The most cases of neonatal jaundice are idiopathic and environmental and inherited factors can affect so they depend on race, genetic polymorphisms; inherited and acquired defects e.g. spherocytosis, Gilbert's syndrome, Najjar 1 and $2 .^{8}$ Pakistan is a resource-constrained nation which makes effective screening and early treatment paramount in managing a public health issue. However, very little research has been done on this particular issue despite the fact that $27.6 \%$

\section{DOW University of Health Sciences, Karachi \\ 2.Student Dow Medical College, Karachi}

Correspondence: Dr Syeda Hina Abbas

Department of Pathology, Dow University of Health Sciences,

Karachi

Email:hina.abbas@duhs.edu.pk

Cell\# 03323779503 infants in Pakistan develop jaundice every year ${ }^{9}$ and we've relied almost exclusively on foreign literature. Even though East Asians have higher baseline neonatal bilirubin levels than whites and are predisposed to the development of severe neonatal hyperbilirubinemia. ${ }^{10}$

Our primary goal is to isolate important prognostic factors in the management of hyperbilirubinemia while our secondary objective is to search for factors affecting the severity of presentation in these patients. We hope our findings will allow us to improve current management guidelines.

\section{MATERIALAND METHODS}

It was a retrospective cross sectional study, conducted during the period of June 2017 and November 2017. Patients aged below one month clinically diagnosed with jaundice and admitted in paediatric unit 3 of civil hospital were selected. Patients who were hospitalized for other reasons and then later developed jaundice, or those with comorbidities were excluded from the study. After taking permission from Head of Department, we looked at patients' records and filled out our proforma to collect data on gender, age, birth weight, blood group incompatibility, and breast feeding. Sampling technique was Non-probability purposive. The sample size in this study was 255 and was calculated using openepi.com based on the findings of Tikmani SS at al. in $2010^{11}$. We used SPSS 16.0 for frequencies and distributions. We ran Chi-square for qualitative variables and student $T$ tests to look for quantitative variables and significant relationships. P-values under 0.05 were taken as significant. 


\section{RESULTS}

Table 1 compares the characteristics of infants that developed kernicterus with those who did not develop kernicterus. Both groups are comparable with respect to sex, however, a relationship between the birth weight and kernicterus was found with a higher incidence of kernicterus in infants with low birth weight $(p=0.004)$. Preterm infants were also seen to be more likely to develop kernicterus; 18 preterm infants developed kernicterus compared to only 4 term infants $(p=0.0000)$.

During the 6-month study period, 255 cases were reviewed. Of these jaundiced neonates, having an average age of $4.79 \pm 1.20$ days, $7(2.7 \%)$ were very low birth weight $(<1.5 \mathrm{~kg}), 129(50.2 \%)$ were low birth weight $(<2.5 \mathrm{~kg})$ and $100(39.2 \%)$ were preterm (<37 weeks). The male-to-female ratio was $1.39: 1$ and the mean age of appearance of jaundice was $2.48 \pm 1.32$ days. Phototherapy was the most common treatment, used in 234 (91.8\%) cases, while $21(8.2 \%)$ were only given supportive treatment. $204(80 \%)$ cases were resolved, $5(2 \%)$ were referred, $30(11.8 \%)$ left against medical advice and 16 (6.3\%) died, 9 of which had developed kernicterus before death. Only 41 $(16 \%)$ infants had anemia out of which 6 expired. Out of the remaining 214 infants that did not have anemia 10 expired. This shows that infants that presented with anemia had a poorer prognosis. A statistically significant relationship was also found between age and the outcome; the infants in Age Group 3(9days and above) had the worst prognosis with 3 out of 10 infant being deceased $(30 \%)$. The majority of the infants were of Age Group 2 (4-9 days) which had no deaths; however, Age Group 1 (0-4) had a death rate of $10.7 \%$.

Table 1. Total no of cases analysed are $255(n=255)$

\begin{tabular}{|c|c|c|c|c|}
\hline & kernicterus & Anemia & Birth Weight & Therapy \\
\hline TOTAL & & & VLBW=7(2.7\%) & Supportive=21(8.2\%) \\
NO OF & YES=22(8.6\%) & Yes=41(16.1\%) & LBW=129(50.6\%) & Phototherapy=234(91.8\%) \\
cases & $\mathrm{NO}=233(91.4 \%)$ & $\mathrm{NO}=214(83.9 \%)$ & NBW=119(46.7\%) & \\
\hline
\end{tabular}

Table 2. Features of resolved and deceased cases

\begin{tabular}{|c|c|c|c|c|}
\hline & kernicterus & Anemia & Birth Weight & Therapy \\
\hline $\begin{array}{c}\text { Resolved } \\
\text { cases } \\
(\mathrm{n}=205)\end{array}$ & $10(4.9 \%)$ & $35(17.1 \%)$ & $\begin{array}{c}\text { VLBW=6(2.9\%) } \\
\text { LBW=103(50.2\%) } \\
\text { NBW=96(46\%) }\end{array}$ & $\begin{array}{c}\text { Supportive=13(6.3\%) } \\
\text { Phototherapy=192(93.7\%) }\end{array}$ \\
\hline $\begin{array}{c}\text { Deceased } \\
\text { cases( } \\
n=17)\end{array}$ & $9(52.9 \%)$ & $6(35.3 \%)$ & $\begin{array}{c}\text { VLBW=1(5.9\%) } \\
\text { LBW=8(47.1\%) } \\
\text { NBW=8(47.1\%) }\end{array}$ & $\begin{array}{c}\text { Supportive }=1(5.9 \%) \\
\text { Phototherapy=16(94\%) }\end{array}$ \\
\hline
\end{tabular}




\section{DISCUSSION}

Pakistan is among those top 10 countries which have largest number of neonatal deaths worldwide and among the top 15 causes of this mortality, one important is bilirubin induced mortality. ${ }^{12,}{ }^{13}$ Although other cause of neonatal mortality are more prevalent like birth asphyxia, intrapartum complication but one can't deny the contribution of neonatal jaundice for increasing mortality. ${ }^{12}$ After birth 3 to 6 days are critical for NNJ as serum bilirubin level peaks during this period. ${ }^{14}$

If it is detected, monitored and managed timely then mortality can be reduced but in resource limited countries timely diagnosis as well as management is compromised as most mothers either don't pay attention because of lack of awareness and if they get access to health facilities the management is hampered by financial factors of the several variables tested, our research focused on variables that have prognostic significance. The variables in question are the presence of kernicterus, anemia along with the severity of hyperbilirubinemia, the age group of the patient, and the modality of treatment employed. Among those who developed kernicterus only $10(4.9 \%)$ cases survived while 9(52.9\%) patients with kernicterus failed to survive in spite of giving phototherapy.

Kernicterus is well known complication of jaundice in which indirect bilirubin level rises to much to get access to brain by crossing blood brain barrier hence badly effecting the prognosis. Kernicterus is a well-known complication of neonatal hyperbilirubinemia. Its adverse effect on outcome was also a prominent finding in the work of Hameed NN et al. carried out in Iraq ${ }^{15}$. Kernicterus is directly related to level of indirect hyperbilirubinemia so it is of no surprise that severity of hyperbilirubinemia also effect prognosis indirectly by unswervingly effecting development of kernicterus shown by other studies as well the severity of hyperbilirubinemia is also a well-recognized prognostic factor as proven by several studies including one conducted by Kuzniewicz MW et al. in $2009^{16}$. Phototherapy is a well-known treatment modality for managing Neonatal jaundice. Its use in developed countries like USA is increasing considering it a safe modality in treating jaundice in neonatal group. In our study phototherapy is given to $91.8 \%$ cases out of which $192(82.1 \%)$ were resolved and $9.4 \%$ had kernicterus. Out of
17 cases which failed to survive 16 were given phototherapy but shows no improvement so effect of phototherapy alone can't improve survival other modalities like severity of hyperbilirubinemia, anemia, and birth weight have strong impact on outcome of disease. in addition, the relationship between treatment modality and outcome is not only intuitive, but well established in literature ${ }^{17}$. We find that that there is a dearth of literature on the effects of thrombocytopenia, leukopenia, and anemia on outcomes in cases of neonatal hyperbilirubinemia even though their prognostic utility in other scenarios have been thoroughly researched ${ }^{18,19}$. Our secondary findings include the severity of presentation of neonatal hyperbilirubinemia being closely related to birth weight and gestational age. This finding ties in well with what several other authors have found $^{20,21}$.

\section{CONCLUSION}

This study concluded many factors affect the outcome of neonates with hyperbilirubinemia. These include the presence or absence of kernicterus, anemia, the type of therapy provided, the birth weight of the infant and the severity of hyperbilirubinemia. Moreover, it was also found that the birth weight and gestational age of the infant influenced the severity of presentation.

\section{RECOMMENDATIONS}

Based on our findings, we would like to recommend updates to the current management guidelines where the aforementioned prognostic factors are given paramount importance in deciding whether we treat as opposed to waiting for spontaneous resolution, how closely/regularly we monitor the patient, which patients need hospital admission, and which factors should be tackled by policy changes to affect positive change on a larger scale.

\section{LIMITATIONS}

Although this study was carefully prepared, we are aware of its limitations. First of all, this study is conducted on a small sample size. Secondly, Civil Hospital Karachi sees patients mostly from the lower socioeconomic group. For more accuracy, the study should also involve patients who did not require admission and those who were admitted in other Paediatrics Units of Civil Hospital Karachi, along with patients in other hospitals of Karachi. Thirdly, about 12 percent of patients could not reach their potential outcome as they Left against 
Medical Advice (LAMA). Lastly, due to a lack of facilities or finances for further investigations such as Coomb's test, and serum levels of G6PD and Alkaline Phosphatase, the causes of Jaundice were not explored and hence could not be included in this study.

\section{REFERENCES}

1. Rennie J, Burman-Roy S, Murphy MS. Neonatal jaundice: summary of NICE guidance. BmJ. 2010 May 19;340:240-9.

2. Najib KS, Saki F, Hemmati F, Inaloo S. Incidence, risk factors and causes of severe neonatal hyperbilirubinemia in the South of iran (fars province).Iranian Red Crescent Medical Journal. 2013 Mar;15(3):260.

3. Olusanya BO, Osibanjo FB, Mabogunje CA, Slusher $\mathrm{TM}$, Olowe SA. The burden and management of neonatal jaundice in Nigeria: A scoping review of the literature. Nigerian journal of clinical practice. 2016;19(1):1-7.

4. Greco C, Arnolda G, Boo NY, Iskander IF, Okolo AA, Rohsiswatmo R, Shapiro SM, Watchko J, Wennberg RP, Tiribelli C, Zabetta CD. Neonatal jaundice in lowand middle-income countries: lessons and future directions from the 2015 don ostrow trieste yellow retreat. Neonatology. 2016;110(3):172-80.

5. Olusanya BO, Ogunlesi TA, Slusher TM. Why is kernicterus still a major cause of death and disability in low-income and middle-income countries?. Archives of disease in childhood. 2014 Dec 1;99(12):1117-21.

6. Bradley A. Neonatal jaundice. Embryo Project Encyclopedia. 2017 Feb 23.

7. Hodgson JM, van Someren VH, Smith C, Goyale A. Direct bilirubin levels observed in prolonged neonatal jaundice: a retrospective cohort study. BMJ paediatrics open. 2018;2(1).

8. Ullah S, Rahman K, Hedayati M. Hyperbilirubinemia in neonates: types, causes, clinical examinations, preventive measures and treatments: a narrative review article. Iranian journal of public health. 2016 May;45(5):558.

9. Khan M, Altaf Malik K, Hayat U. ABO Incompatibility in Neonates Coming to a Pediatric Tertiary Care Hospital. Pakistan Journal of Medical Research. 2016 Oct $1 ; 55(4)$.

10. Castillo A, Grogan TR, Wegrzyn GH, Ly KV, Walker VP, Calkins KL. Umbilical cord blood bilirubins, gestational age, and maternal race predict neonatal hyperbilirubinemia. PloS one. 2018 Jun 1;13(6):197888.
11. Tikmani SS, Warraich HJ, Abbasi F, RizviA, Darmstadt GL, Zaidi AK. Incidence of neonatal hyperbilirubinemia: a population-based prospective study in Pakistan. Tropical Medicine \& International Health. 2010 May 1;15(5):502-7

12. Liu L, Oza S, Hogan D, et al. Global, regional, and national causes of under-5 mortality in 2000-15: an updated systematic analysis with implications for the Sustainable Development Goals. Lancet. 2016;388(10063):3027-3035

13. Alkema L, Chou D, Hogan D, Zhang S, Moller AB, Gemmill A, Fat DM, Boerma T, Temmerman M, Mathers C, Say L. Global, regional, and national levels and trends in maternal mortality between 1990 and 2015, with scenario-based projections to 2030: a systematic analysis by the UN Maternal Mortality Estimation Inter-Agency Group. The Lancet. 2016 Jan 30;387(10017):462-74.

14. United Nations Children's Fund (UNICEF). The State of the World's Children 2016. A Fair Chance for Every Child. New York, NY: United Nations Children's Fund (UNICEF); 2016

15. Hameed NN, Vilms R, Bhutani VK. Severe neonatal hyperbilirubinemia and adverse short-term consequences in Baghdad, Iraq. Neonatology. 2011;100(1):57-63

16. Kuzniewicz MW, Escobar GJ, Newman TB. Impact of universal bilirubin screening on severe hyperbilirubinemia and phototherapy use. Pediatrics. 2009 Oct 1;124(4):1031-9.

17. Olusanya BO, Teeple S, Kassebaum NJ. The contribution of neonatal jaundice to global child mortality: findings from the GBD 2016 study. Pediatrics. 2018 Feb 1;141(2):20171471.

18. Hui P, Cook DJ, Lim W, Fraser GA, Arnold DM. The frequency and clinical significance of thrombocytopenia complicating critical illness: a systematic review. Chest. 2011 Feb 1;139(2):271-8.

19. Naseem S, Varma N, Das R, Ahluwalia J, Sachdeva MU, Marwaha RK. Pediatric patients with bicytopenia/pancytopenia: review of etiologies and clinico-hematological profile at a tertiary center. Yndian Journal of pathology and microbiology. 2011 Jan 1;54(1):75.

20. Maisels MJ, Watchko JF, Bhutani VK, Stevenson DK. An approach to the management of hyperbilirubinemia in the preterm infant less than 35 weeks of gestation. Journal of perinatology. 2012 Jun 7;32(9):660.

21. Okwundu $\mathrm{Cl}$, Okoromah CA, Shah PS. Cochrane Review: Prophylactic phototherapy for preventing jaundice in preterm or low birth weight infants. Evidence-Based Child Health: A Cochrane Review Journal. 2013 Jan;8(1):204-49. 